\title{
ESPAÇO, INOVAÇÃO E INDÚSTRIA TÊXTIL DE REDES DE DORMIR EM SÃO BENTO-PB: DO MEIO NATURAL AO MEIO TÉCNICO-CIENTÍFICO- INFORMACIONAL
}

\author{
ROSALVO NOBRE CARNEIRO ${ }^{1}$ \\ Universidade do Estado do Rio Grande do Norte
}

Indústria têxtil e inovação em São Bento-PB: situando a questão central

Do ponto de vista das inovações periodizamos a indústria têxtil do município de São Bento nas fases do artesanato, manufatura e da maquinofatura. Ela evoluiu da fase artesanal, dominante no início do século XX, para a manufatura no final da década de 1950, e, pós-1980, se encontra em seu estágio industrial (CARNEIRO, 2001). Com base nesta evolução e nos processos inovadores que configuram cada fase, estabelecemos uma periodização também para o meio geográfico local, assim, a fase artesanal correspondeu a um meio técnico; a manufatureira, a um meio técnico-cientifico; e a maquinofatureira, ao meio técnicocientífico-informacional atual (CARNEIRO, 2011). A indústria têxtil de redes de dormir ou os proprietários dos meios de produção, para usar os termos empregados por Corrêa (1991), são, do ponto de vista desse estudo, os agentes centrais da inovação e, consequentemente, da formação do meio técnico-científico-informacional de São Bento-PB (Figura 1). Por isso busca-se, através da descrição de seu processo de mecanização, destacar as relações entre as inovações empreendidas por esse segmento do capital industrial e a constituição de seu meio geográfico, com a incorporação de técnicas, ciências e informação ao território.

\footnotetext{
${ }^{1}$ Professor Permanente do Programa de Pós-graduação em Ciências Sociais e Humanas PPGCISH, da UERN. Doutor em Geografia pela UFPE. Email: rosalvonobre@hotmail.com
} 


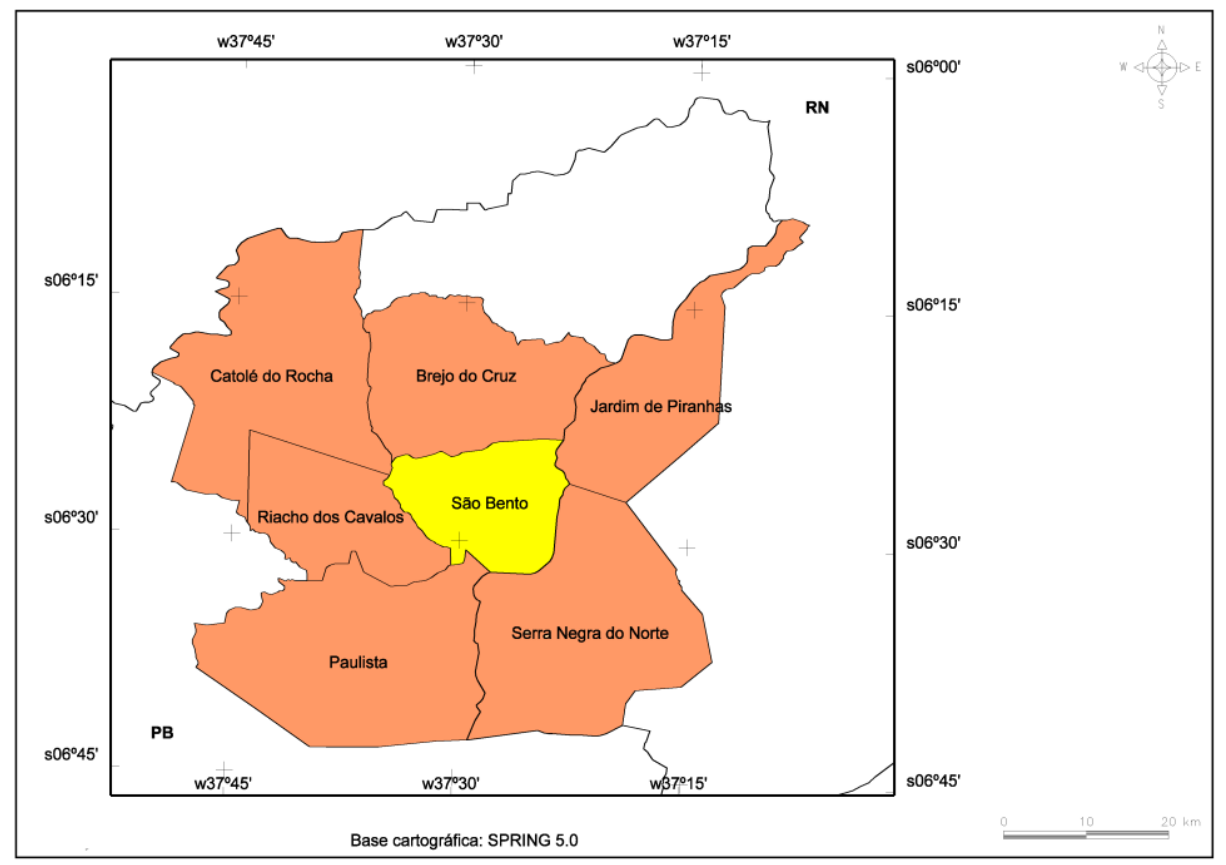

Figura 1: São Bento-PB: localização e limites geográficos.

Elaboração: Carneiro (2013).

Esse estudo é um recorte temático de discussões empreendidas em trabalhos anteriores (CARNEIRO, 2001; 2006; 2011), com foco, porém, nas inovações não tratadas de forma central naqueles mesmos trabalhos. Diversas pesquisas de campo foram realizadas em diferentes períodos para a obtenção de dados que subsidiassem os trabalhos citados: a) no ano 2000, especialmente junto a mais de 500 trabalhadores das fábricas de São Bento; b) em 2003, com feirantes e empresários não fabricantes de redes de dormir ligados ao setor - como comerciantes de matérias-primas e equipamentos; e, c) em 2010, com o conjunto de atores sociais dessa indústria, desta vez não apenas em São Bento, mas também em outros municípios produtores de redes de dormir e produtos substitutos na região. Como ilustra a imagem a seguir: 


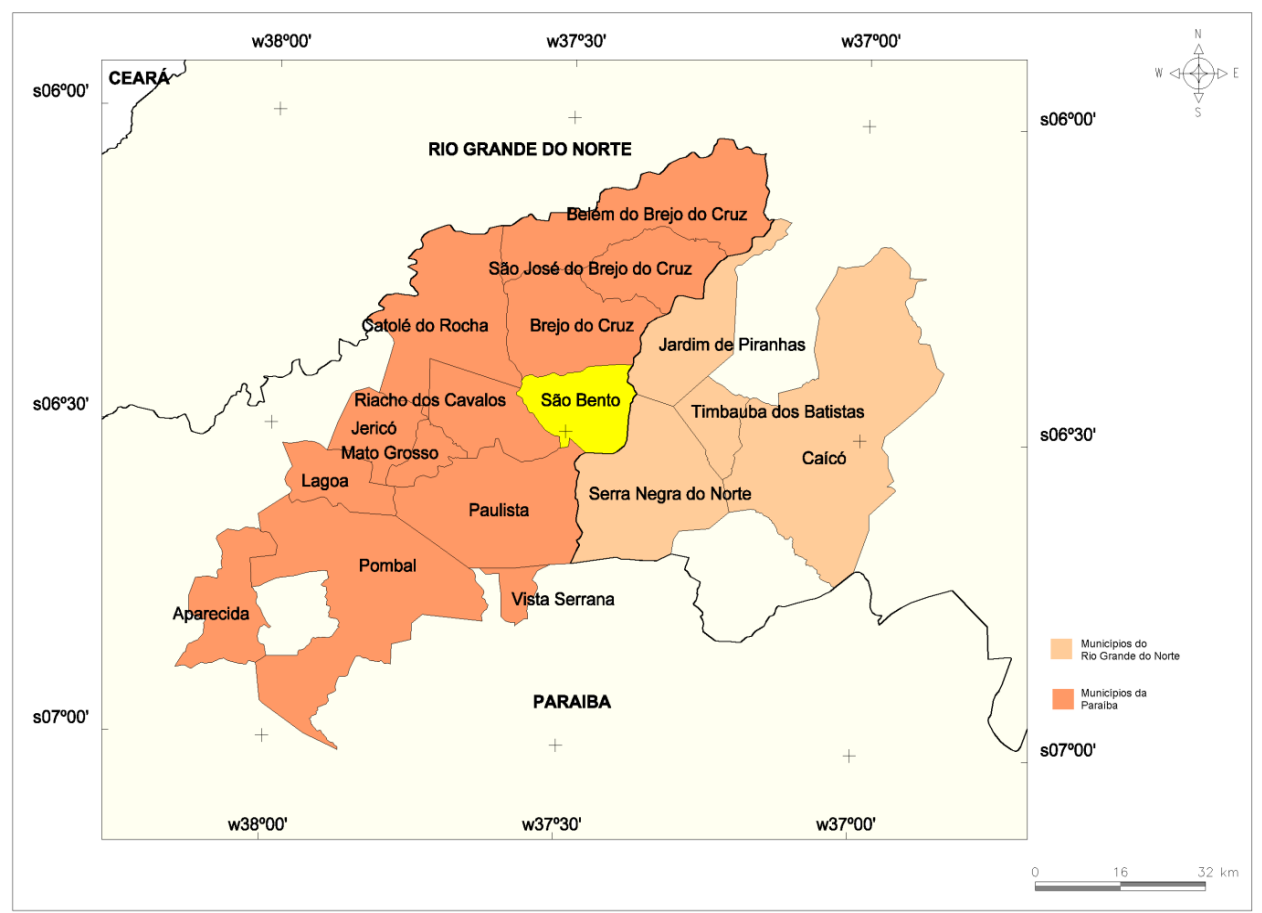

Figura 2: São Bento: espaços formadores do circuito espacial da produção regional da indústria têxtil.

Fonte: Carneiro (2011).

Este espaço foi, ao mesmo tempo, a condição e o resultado do processo de inovação técnica, produtiva e organizacional do artesanato de redes de dormir de São Bento; do desenvolvimento do circuito de fluxos inferior informal da sua indústria têxtil; do circuito local e regional da produção; do avanço horizontal do seu meio técnico, e, como consequência desses eventos, da organização do seu período técnico artesanal.

Em junho de 1932 resolvi fazer ambulância com redes, a primeira feira foi em Pombal, aí tinha um colega de Buqueirão de Cabaceiras, também ambulante, vendia rede de um pano [...], fiquei admirado de ver aquilo [...]. Em Paulista, conversando com o colega, me deu umas explicações sobre a 
tecelagem [...] isto em 1933. Resolvi modificar meu tiazinho para um de um pano só, [...]. Em 1938 José Lucio montou uma fábrica de rede em Pombal, com 6 tiares que dava o nome de batelão, eu fui olhar a fábrica achei muito interessante, levei logo o pensamento em fazer um, encomendei o pente, lançadeira e espola (Depoimento apud ROCHA, 1983, p. 127-128, grifos do autor).

Dividimos o texto em três seções. Na primeira, Origem da indústria têxtil de São Bento e formação do seu meio técnico (1889-1958), descrevemos o processo que origina o artesanato local e como as suas inovações configuram aquele meio técnico. $\mathrm{Na}$ segunda - $O$ período manufatureiro, inovações e produção do meio técnico-científico de São Bento (1959-1980) - destacam-se as inovações técnicas, das quais a central é o aparecimento da manufatura local e a imposição espacial do meio técnico-científico pela presença da ciência no processo de produção e no território. Por fim, na terceira seção - Maquinofatura, meio técnicocientífico-informacional e inovações em São Bento - analisamos o conjunto atual de inovações propiciadas pela constituição do meio técnicocientífico-informacional local, cujos objetos e território passam a ser dotados também de informação.

\section{Origem da indústria têxtil de São Bento e formação do seu meio técnico (1889-1958)}

No período artesanal da indústria têxtil de São Bento o artesão tinha o controle total dos meios de produção e do processo de trabalho, podendo, desse modo, decidir sobre quando, onde e quanto produzir em função de suas necessidades. Analisando a história mundial da indústria, Harnecker disserta acerca de seu período artesanal:

$\mathrm{O}$ processo de trabalho individual caracteriza-se, fundamentalmente, porque nele existe uma clara unidade do trabalhador e de seu meio de trabalho. [...] Por outro lado, e de acordo com o que foi dito anteriormente, é ele quem controla todo o processo de trabalho ou o tem sob domínio absoluto. Decide como, quando e onde deve trabalhar (1983, p. 46).

As fábricas em São Bento se localizavam na própria residência do trabalhador artesão, coisa que, sob essa perspectiva, impedia a expansão do 
seu meio técnico. Pois de um lado tratava-se inicialmente de uma atividade de autoconsumo e que não carecia ao seu funcionamento da construção de objetos técnicos mais modernos para essa atividade, coisa que possivelmente ocorreria se se localizassem distantes do seu local de moradia. Segundo Séris (apud SANTOS, 1999, p. 32) “[...] será objeto técnico todo objeto suscetível de funcionar, como meio ou como resultado, entre os requisitos de uma atividade técnica". Desse ponto de vista, para Santos (1999), quanto mais o objeto técnico se distancia da natureza se tecnificando, mais perfeito ele é, pois deste modo permite um comando maior do homem sobre ele.

Nesse período, entretanto, a expansão do artesanato foi limitada a algumas unidades familiares através do controle exercido sobre elas pelos comerciantes de fios de algodão industrializados, em função da difusão dessa matéria-prima naquele espaço, trazida à época das fiações instaladas em Campina Grande, Natal e Mossoró. E propiciada pela melhora relativa da rede de transportes que conectava São Bento a esses centros. Esse fato acabou impedindo que a manufatura fosse implantada vários anos antes de sua instalação em São Bento. Segundo Rocha, esse evento não logrou em função de duas razões:

A primeira foi que o controle do comércio de fio permaneceu nas mãos dos comerciantes que exploravam o sistema de produção doméstico; em segundo lugar, a comercialização das redes também permaneceu centralizada. Em outras palavras, tanto o abastecimento da matéria-prima quanto a venda do produto acabado continuavam tendo que passar pela meia dúzia de prósperos mercadores aos quais não interessava perder o controle da atividade. Dessa forma, não havia vantagem em estabelecer mais um elo na cadeia de produção (1983, p. 43-43).

O estabelecimento desse novo elo na cadeia produtiva, isto é, a manufatura, já por essa época poderia ter permitido o aprofundamento das relações entre a sociedade local e sua natureza e possibilitado, dessa forma, uma produção mais dinâmica do seu meio técnico. Destarte, o meio natural se sobressaía na paisagem humanizada de então, sendo os objetos naturais em maior quantidade que os objetos técnicos móveis e imóveis. Essa situação mostra claramente que até as primeiras décadas do século XX as relações entre a sociedade local e o espaço nacional eram baseadas em relações de contiguidade com espaços vizinhos, cujas trilhas e caminhos mantinham um papel determinante na circulação de pessoas, mercadorias, 
ideias, mensagens e ordens, enfim, na difusão das inovações. Essa relação, do ponto de vista da interação homem/natureza, era respeitosa e equilibrada, em função das próprias técnicas de produção existentes no espaço.

Foram essas redes frágeis que, permitindo o deslocamento lento e o contato forte da população local com as de diferentes áreas da Paraíba e do Rio Grande do Norte para a troca de excedentes agrícolas, mediada pelas feiras das cidades mais antigas e dinâmicas da região, - principalmente Pombal, Catolé do Rocha e Patos (na Paraíba); Caicó (no Rio Grande do Norte); e, em menor frequência, Campina Grande e Mossoró nesses respectivos estados - possibilitaram a difusão de inovações em São Bento. Das quais a mais importante foi a chegada do artesanato de redes de dormir, no final do século XIX. Como assinala Dias:

Toda a história das redes técnicas é a história de inovações que, umas após as outras, surgiram em resposta a uma demanda social antes localizada do que uniformemente distribuída. Com a ferrovia, a rodovia, a telegrafia, a telefonia e finalmente a teleinformática, a redução do lapso de tempo permitiu instalar uma ponte entre lugares distantes: doravante eles serão virtualmente aproximados (2000, p. 141, grifo nosso).

A rede de comunicações se constituía de forma extremamente precária em São Bento, na virada para o século XX. Particularmente, em 1922 ocorre a instalação de uma agência dos Correios no município, sendo esse evento representativo dos primórdios da constituição do sistema de comunicações que foi responsável por conectar a área em questão através dos fluxos de informação, a espaços distantes. Ainda no início dessa década, a agência dos Correios inaugura a instalação do telégrafo, colocando em contato de forma mais rápida e eficiente o espaço local ao resto da região circundante. A difusão local deste objeto técnico é, todavia, resultante da estruturação do espaço nacional, visando a sua integração territorial e a difusão dos valores da região central do país ao restante da nação.

Cinco anos mais tarde inaugura-se o Mercado Público da cidade, evento que denota a importância que o artesanato começa a adquirir em função do crescimento da atividade e da produção, propiciado pela ampliação de redes de troca regionais, da qual o símbolo maior foi a passagem da realização semanal de uma feira que até então era mensal. 
A rede de energia, ausente até o início da segunda metade do século $\mathrm{XX}$, é difundida inicialmente com a implantação de um gerador elétrico cujo funcionamento se dava entre 18:00 e 22:00 horas, em alguns dias da semana. Esse objeto técnico não propiciou condições para a mecanização da indústria têxtil, embora tenha contribuído indiretamente para ampliação da produção pois permitiu que a atividade pudesse se realizar em período noturno e, tendo em vista a sua característica artesanal, parece ter se constituído em alternativa para ampliação dos lucros.

A rede de transportes capaz de ligar a área ao restante do Nordeste era relativamente favorável em direção à capital do estado e ao litoral oriental. Porém precária na distribuição das mercadorias através do interior e, em épocas de chuvas, pela incapacidade dos veículos em atravessar o rio Piranhas - que corta o município de oeste a leste -, o que forçava a mudança de percurso para áreas distantes, encarecendo o produto em função de uma distribuição ineficiente.

A partir das décadas de 1930 e 1950, sobretudo, o meio técnico local se amplia e se torna mais complexo em função da evolução da atividade fabril, que, embora ainda artesanal, sofre alteração estrutural em função das inovações técnicas no processo produtivo. Rocha fez a seguinte descrição acerca desta mudança:

Os comerciantes passaram a encomendar teares que eram
entregues, já aparelhados, às pessoas que se dispusessem a
trabalhar sob contrato, isto é, recebendo o fio (e
eventualmente tintas) e comprometendo-se a entregar
determinada quantidade de redes acabadas, num sistema que
diferenciava-se da produção doméstica clássica ou putting out
system unicamente pelo fato de que os artigos eram
integralmente confeccionados na casa de um único artesão.
Em outras palavras, a mercadoria não "circulava", tal como
na produção de roupas através desse sistema citado (1983, p.
42).

A complexificação crescente do meio técnico nesse período foi resultado dessa inovação na estrutura do sistema produtivo da introdução do fio industrializado, em contraposição com a fiação manual do algodão, além do emprego de instrumentos de trabalho relativamente mais modernos, embora ainda manuais, e de técnicas mais avançadas de produção como a implementação da divisão simples do trabalho. A divisão técnica do trabalho nas unidades familiares de produção ocorre já na passagem da década de 20 para a de 30, devendo, segundo Rocha (1983, p. 
[...] ter tido alguma relação com a introdução mais ou menos nessa mesma época do chamado tear batelão, isto é, um tear largo que permite tecer o pano na largura apropriada para a confecção da rede e inclui o uso da lançadeira. O tear batelão é maior, mais pesado e exige um grande esforço físico para a sua operação.

Esses fixos e fluxos se encontravam representados pelos depósitos de fios de algodão e, ampliavam a capacidade de obtenção de matéria-prima básica por parte dos pequenos artesãos, da venda de tintas pelas mercearias ou bodegas, da compra de matérias-primas auxiliares, de marcenarias que davam margem à construção em menor tempo dos instrumentos de trabalho - teares, espuladeiras, conicaleiras -, além de pessoas dedicadas exclusivamente à venda das redes de dormir em feiras livres de outras áreas. Envolvendo, desse modo, maior contingente da população local nessa atividade, uma ampliação do espaço construído e o aumento de intercâmbios para a aquisição de bens e serviços necessários à vida (Figura 3). Inovações importantes se deram também no processo de tinturaria, com a introdução das tintas artificiais. Por outro lado, algumas peças e acessórios para tear, como lançadeiras, eram adquiridas em Mossoró importante centro têxtil da primeira metade do século passado -, garantindo, com esse conjunto de eventos, a dissociação geográfica da produção e a condição para a ampliação do acontecer complementar entre São Bento e espaços distantes.

O espaço tinha um peso importante na dinâmica da atividade têxtil de São Bento pois durante o seu período artesanal ela se concentra notadamente na zona rural, mais especificamente, na moradia do agricultor-artesão. A quantidade de fixos e fluxos postos para seu funcionamento é limitada - não carecendo investimento de monta - usandose quase sempre os objetos já presentes no meio local para sua operação e realização. É assim que o espaço humano ou o "território usado", para empregar as expressões de Santos e Silveira (2004), introduz um papel ativo no processo de inovação dessa atividade industrial. 


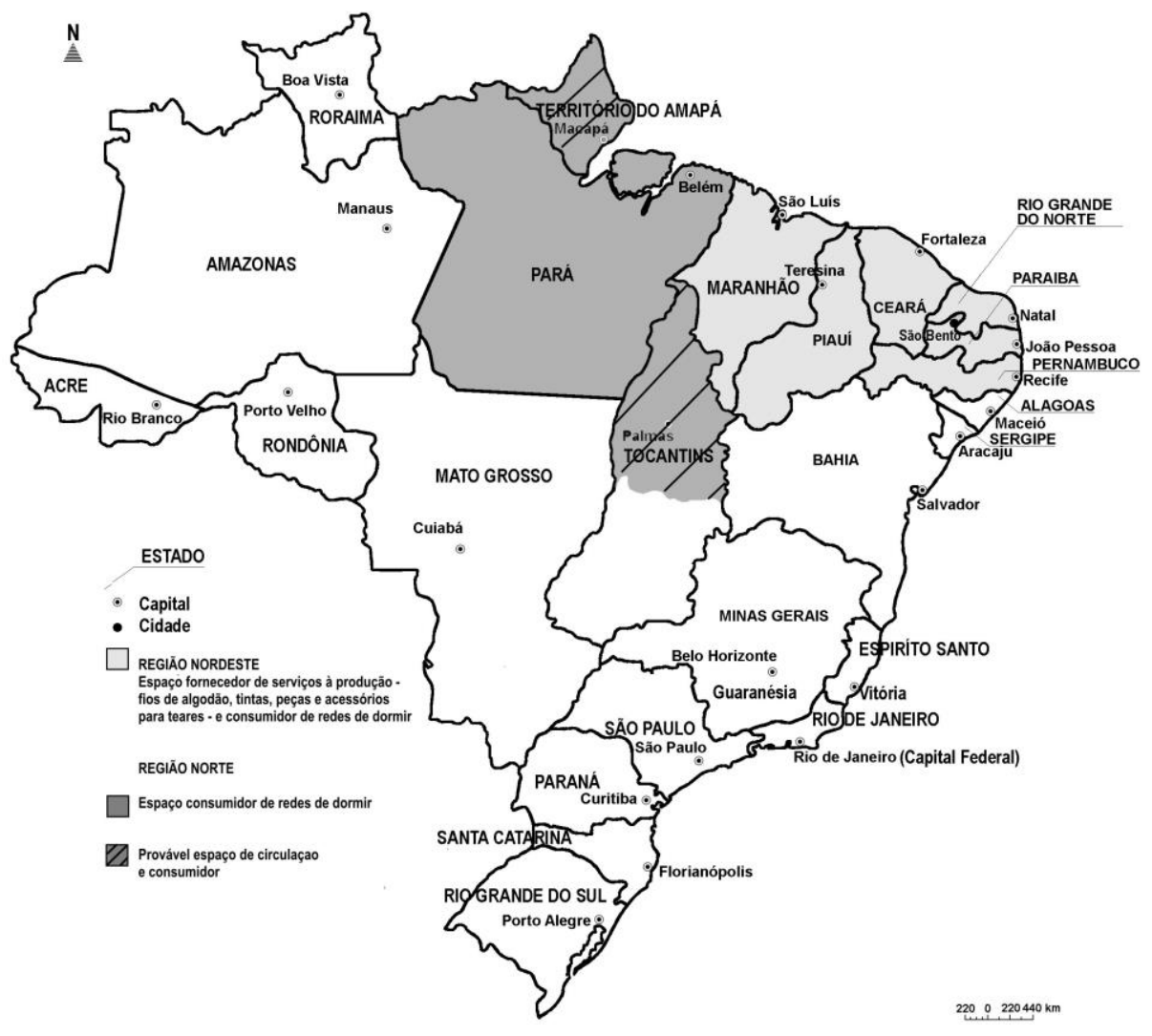

Figura 3: Brasil - área de abrangência do artesanato de São Bento na primeira metade do século XX.

Fonte: Carneiro (2006).

Ressalta-se que, para Santos (1988, p. 77-78), "os fixos são os próprios instrumentos do trabalho e as próprias forças produtivas em geral, incluindo a massa dos homens", enquanto "os fluxos são o movimento, a circulação, e assim eles nos dão a explicação dos fenômenos da distribuição e do consumo". Os fluxos, porém, não podem se realizar se não há uma rede de comunicações adequada às suas características e, desse modo, são um impedimento para uma propagação mais rápida das 
inovações advindas de fora. É nessa perspectiva que, do ponto de vista das grandes inovações aqui trabalhadas - artesanato, manufatura, maquinofatura -, a manufatura se realiza num momento em que os fluxos se aceleram motivados pela ampliação do meio técnico-científicoinformacional nacional, incluindo a modernização das redes capaz de facilitar a difusão mais veloz das inovações nos espaços distantes e interiores do país.

\title{
Período manufatureiro, inovações e produção do meio técnico- científico de São Bento (1959-1980)
}

$\mathrm{Na}$ fase da produção em manufaturas salienta-se que o trabalhador ainda controlava os meios de trabalho, mas não tinha mais o domínio sobre o processo de produção, que se encontrava agora nas mãos do capitalista e do trabalhador coletivo. Harnecker, da mesma forma, analisando a emergência da fase manufatureira do capitalismo global, disse:

\begin{abstract}
Pode existir um processo cooperativo de produção que implique a existência de uma unidade entre o trabalhador $e$ seu meio de trabalho, isto é, em que o trabalho realizado em forma coletiva implique um controle ou domínio, por parte do trabalhador individual, de seu instrumento de trabalho. Nesse caso existe uma separação do trabalhador individual com respeito à colocação em marcha do processo de trabalho que agora está em mãos do trabalhador coletivo, mas há uma união do trabalhador individual com seu meio de trabalho: sua habilidade pessoal continua valendo (1983, p. 47-48, grifos do autor).
\end{abstract}

Eventos importantes se dão localmente e de forma simultânea na década de 1950, simbolizando a relevância da cidade de São Bento em função de sua atividade manufatureira, como a emancipação política frente à Brejo do Cruz (em 29 de abril 1959) e a construção da Prefeitura Municipal já em novembro do mesmo ano, o que garantiu autonomia política da sociedade local a fim de imprimir ao seu espaço um rumo próprio. Um ano antes desse fato a primeira manufatura se instala na cidade com o emprego de 20 teares, concentrando em um mesmo lugar os fixos necessários à produção, instrumentos e homens, e, produzindo em grande quantidade para um mercado ampliado. Assim, nesta época a localidade já contava com quatro das 15 fábricas de redes de dormir existentes na Paraíba. 
A manufatura que se estabelece no município consolida aí a divisão social do trabalho. Os homens passaram a se dedicar à primeira fase da produção, já que esta envolve maior força física. Ela divide-se em diferentes etapas que no seu conjunto resultarão na confecção de um pano com as dimensões apropriadas para ser transformado em rede de dormir. Tais etapas se consistem na urdição, no alvejamento, no tingimento e tecelagem do fio, entre outras. As mulheres passam a se dedicar essencialmente à segunda fase da produção, chamada de acabamento, e que corresponde à confecção do fio já tecido (pano) em rede de dormir. Nessa última, no entanto, era comum e ainda é, a presença de homens, enquanto na primeira é menos evidente a presença feminina, mas de qualquer forma também existente. Essa divisão do trabalho desenvolvida e ampliada na manufatura de São Bento, nas palavras de Marx, gera uma

[...] diferenciação dos instrumentos de trabalho - uma
diferenciação pela qual os implementos de dado tipo
adquirem formas fixas, adaptadas a cada situação particular;
[... simplifica, melhora e multiplica os implementos de
trabalho, adaptando-os às funções exclusivamente especiais
de cada trabalhador especializado. Cria assim, ao mesmo
tempo, uma das condições materiais para a existência da
máquina, que consiste em uma combinação de instrumentos
simples (MARX, [s.d.] apud DOBB, 1983, p. 104).

A criação da primeira manufatura no espaço de pesquisa é um marco importante para a história da atividade local, sobretudo para explicar o dinamismo que a indústria têxtil em São Bento adquiriu posteriormente, inclusive obtendo teares mecânicos em meados da década de 60, antes mesmo de possuir energia elétrica, enquanto a tecelagem em Fortaleza muito mais antiga e tradicional - só iria iniciar a mecanização da produção em 1979 (ROCHA, 1983, p. 46-47). Esses fatos juntos podem ser vistos como responsáveis pela produção, transformação e reorganização do espaço de São Bento, ou seja, é nos marcos do processo de mecanização da indústria têxtil de São Bento que o seu processo de (re)produção do espaço se desenvolve e se acentua. A evolução e o desenvolvimento da indústria no espaço de pesquisa não representaram apenas transformações de ordem técnica, mas, sobretudo, transformações no seu caráter espacial, ou seja, na sua formação espacial.

Após a segunda Guerra Mundial e principalmente a partir da década de 1960, as redes nacionais dão um salto significativo modernizando-se e contribuindo para a difusão de inovações mais aceleradamente pelo espaço 
nacional, ainda que como na fase anterior, de modo desigual. Como lembra Santos:

\begin{abstract}
as primeiras fases do processo de integração foram concentradoras das atividades modernas e dinâmicas, tanto do ponto de vista econômico quanto geograficamente. É na última fase, quando já existe um capitalismo maduro, que vamos testemunhar a possibilidade de uma difusão da modernização, não só presente quanto aos capitais, como quanto à tecnologia e às formas de organização (1999, p. 37).
\end{abstract}

Examinando a evolução da atividade manufatureira em São Bento se constata que, na virada entre as décadas de 60 e 70, ocorre uma expansão de novas unidades produtivas manufatureiras na cidade, confirmando a existência de uma "coincidência" entre a "a expansão da atividade a nível local", isto é, na área de trabalho, e a recuperação da economia brasileira após a crise de 67/68 (ROCHA, 1983, p. 48), período de início do "milagre econômico brasileiro". Comparando o período com o desenvolvimento da atividade no município de Pedro II, no estado do Piauí, constatou-se que diversos comerciantes de fios de algodão deixaram esse ramo de atividade, por diferentes motivos (ARAÚJO, 1985, p. 101).

Essa evolução verificada na atividade tem, no entanto, suas raízes em momento anterior, com a adoção de inovações. Primeiro a própria criação da manufatura, em 1958, inicialmente com 20 teares de madeira - para os quais a construção exigiu grande capital fixo para sua acomodação, e elevada contratação de mão-de-obra assalariada. Segundo, pela introdução, seis anos mais tarde, dos primeiros teares elétricos no processo produtivo. "Em um mercado competitivo, a escolha de tecnologia adequada e sua introdução ao processo produtivo permite manter uma posição de igualdades, ou mesmo de superioridade com relação aos produtores concorrentes" (RATTNER, 1980, p. 14).

Essas inovações técnicas que se dão mais como uma adaptação de tecnologias usadas em outro período do tempo - a exemplo dos teares elétricos, que já eram empregados na confecção da malharia nas fábricas têxteis de Americana, no estado de São Paulo -, foram possíveis pela expansão e melhoria da configuração territorial do país, pondo São Bento em contato com cidades longínquas, por intermédio das redes técnicas. Desta forma:

A configuração territorial é formada pelo conjunto de sistemas de engenharia que o homem vai superpondo à 
natureza, verdadeiras próteses de maneira, a permitir que se criem as condições de trabalho próprias de cada época. $\mathrm{O}$ desenvolvimento da configuração territorial na fase atual vem com um desenvolvimento exponencial do sistema de transportes e do sistema de telecomunicações e da produção de energia (SANTOS, 1998, p. 141).

Dois eventos ocorridos localmente contribuíram significativamente para a possibilidade de utilização das redes nacionais: a construção de uma ponte sobre o rio Piranhas, em 1971, o que facilitou a ligação com os estados do Norte e do Centro-Oeste; e a implantação, dois anos depois, da rede de telecomunicações, incluindo os telefones. Esses acontecimentos aparentemente banais foram responsáveis por encurtar distâncias e favorecer a mecanização da indústria têxtil local, assim, "O espaço se torna fluido, permitindo que fatores de produção, o trabalho, os produtos, as mercadorias, o capital, passem a ter uma grande mobilidade" (SANTOS, 1999, p. 39).

\section{Maquinofatura, meio técnico-científico-informacional e inovações em São Bento}

A sociedade de São Bento vê na década de 1990 sua indústria têxtil consolidar sua mecanização e, a partir de então, a sua existência depender cada vez mais da constituição do seu meio técnico-científicoinformacional, das inovações que ele acolhe e condiciona, e das possibilidades que o mesmo abre para a utilização das redes internacionais. Na maquinofatura há uma subordinação total por parte do trabalhador em relação à máquina (meios de trabalho) e ao processo de trabalho, passando, desse modo, a seguir o ritmo de trabalho por eles determinado.

Pode haver também o caso de um processo de produção cooperativa em que o trabalhador individual tenha perdido não só o domínio de pôr em marcha o processo de trabalho mas também tenha perdido o domínio do meio de trabalho, como ocorre na grande indústria onde o trabalhador passa a ser uma peça a mais da máquina (HARNECKER, 1983, p. 48).

A perda da importância da utilização dos teares manuais nas tecelagens de São Bento e a sua substituição por teares elétricos na produção consolidou a separação entre a força de trabalho e os meios de 
produção, representando a sua subordinação total ao capital, pois, segundo Marx (1985, p. 483):

$\mathrm{Na}$ manufatura e no artesanato, o trabalhador se serve da ferramenta; na fábrica, serve à máquina. Naqueles, procede dele o movimento do instrumental de trabalho; nesta, tem de acompanhar o movimento do instrumental. Na manufatura, os trabalhadores são membros de um mecanismo vivo. Na fábrica, eles se tornam complementos vivos de um mecanismo morto que existe independente deles.

Se a manufatura surge e pode ser entendida como a reunião de uma "[...] quantidade relativamente grande de operários que trabalha ao mesmo tempo, em um mesmo lugar e sob o comando do próprio capitalista" (HARNECKER, 1983, p. 54) a maquinofatura, ou seja, a indústria moderna

[...] diferencia-se da manufatura pela forma que adquiriu nela o meio de trabalho [...] O processo de produção já não pode ser definido como a reunião de certo número de operários, mas como um conjunto de máquinas dispostas a receber qualquer operário (1983, p. 58-59).

Carlos, de forma simples e objetiva, abordando a questão das relações entre a máquina e o homem, destaca as profundas transformações que ela (a máquina) imprimiu à sociedade, a partir da Revolução Industrial Inglesa ocorrida na segunda metade do século XVIII, mostrando como se inverte o papel do homem no processo produtivo, de agente ativo para "passivo". Diz ela que

[...] a máquina aparece como o elo de transformação, não do modo de produção em outro, mas do homem no processo de trabalho e da mudança do seu papel neste mesmo processo. A máquina, enquanto meio de produção e meio material de existência do capital, passa a ser o fundamento material do modo de produção capitalista. A grande indústria, ao revolucionar as relações gerais de produção da sociedade, produz uma nova concepção de trabalho, de vida, de relações entre os seres humanos. Isto é provocado pela mudança das relações entre o capital e o trabalho, pois a maquinaria de meio de trabalho, converte-se de imediato, em competidor do próprio operário e a habilidade deste desaparece. Não se exige mais que o operário produza algo com uma ferramenta que 
ele maneje com o movimento de seus músculos. Exige-se, isto sim, que ele utilize uma máquina que ditará um novo ritmo de trabalho (1992, p. 30).

O processo de inovação da indústria têxtil de São Bento (Quadro 1) tem como dado explicativo o sistemismo da técnica, pois, como afirma Santos (1999, p. 140-141), os "conjuntos de técnicas aparecem em um dado momento, mantêm-se como hegemônicas durante certo período [...] até que outro sistema de técnicas tome o lugar. Essa é a lógica de sua existência e de sua evolução". Pode-se dizer que a mecanização da indústria têxtil de São Bento é o resultado da irreversibilidade das técnicas, na medida em que estas "[...] em um primeiro momento, são um produto da história e, em um segundo momento, elas são produtoras da história, já que diretamente participam desse processo" (SANTOS, 1999, p.145) 


\begin{tabular}{|c|c|c|}
\hline Período & "Objetos Imperfeitos" & "Objetos Perfeitos" \\
\hline 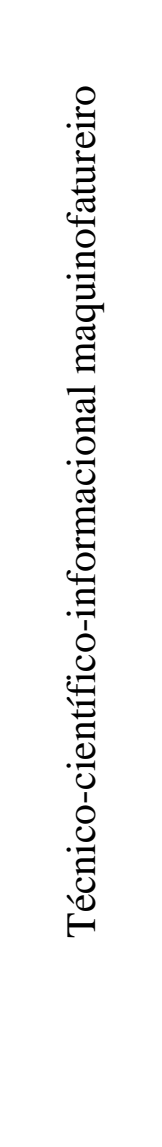 & 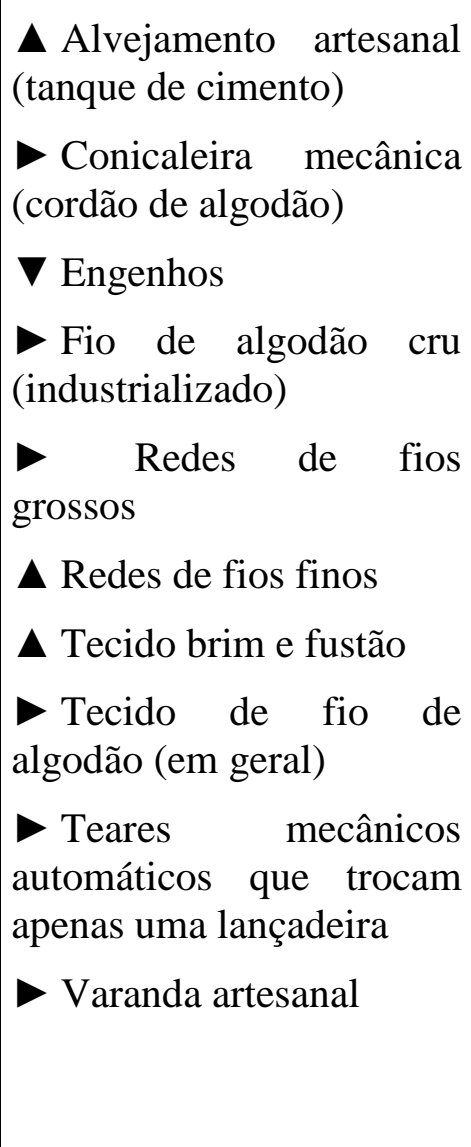 & 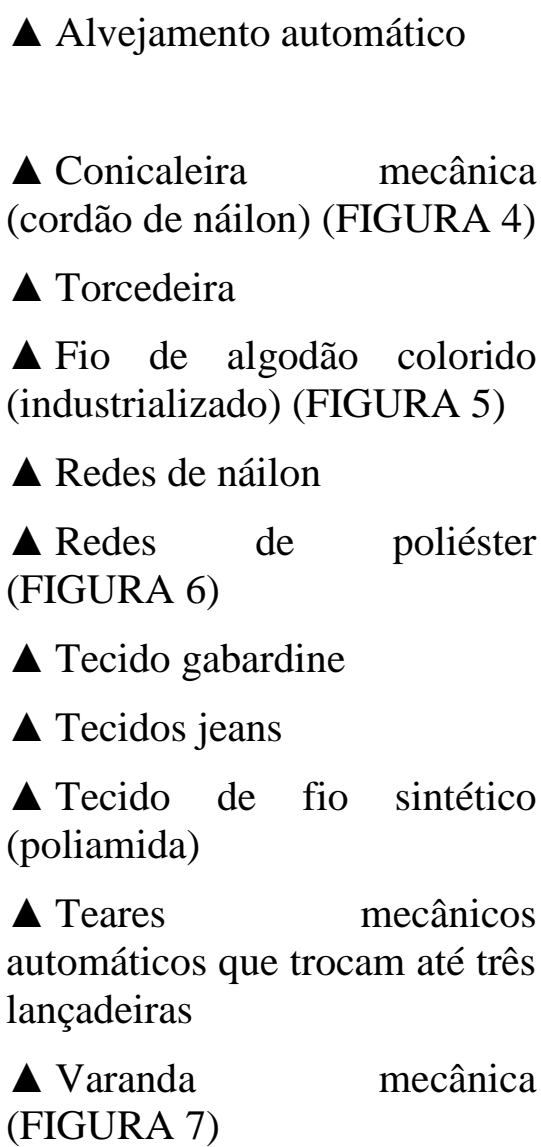 \\
\hline
\end{tabular}

Quadro 1: Inovações no período maquinofatureiro de São Bento.

Fonte: Carneiro (2006).

$\Delta \quad$ Tendência ascendente (real ou potencial);

$\boldsymbol{\nabla}$ Tendência declinante (real, potencial ou obsolescência);

- Tendência estável. 


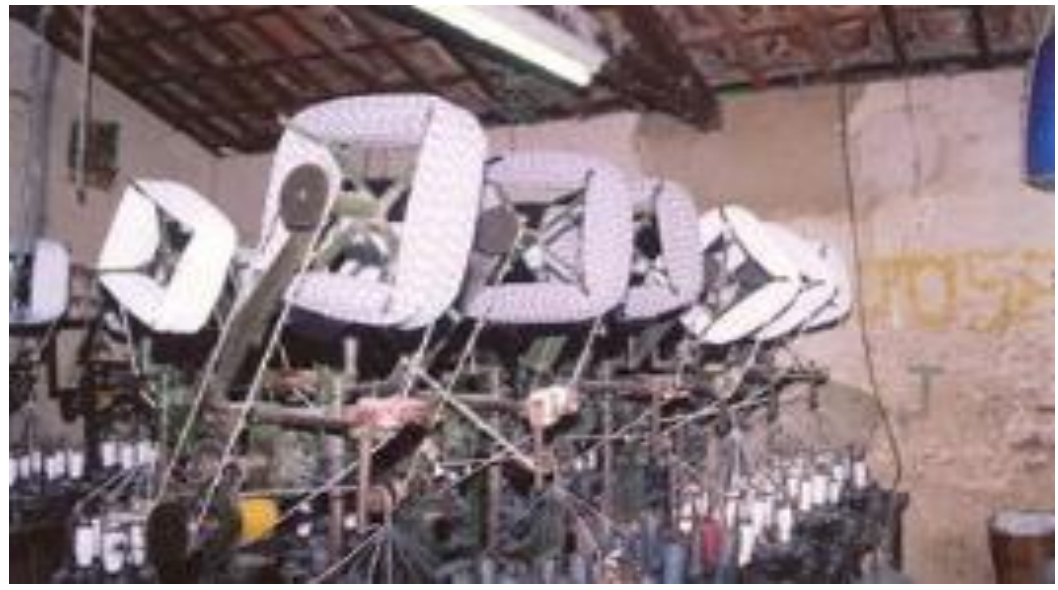

Foto 4: São Bento-PB: conicaleiras fabricando cordões de algodão. Foto: Carneiro, 2006.

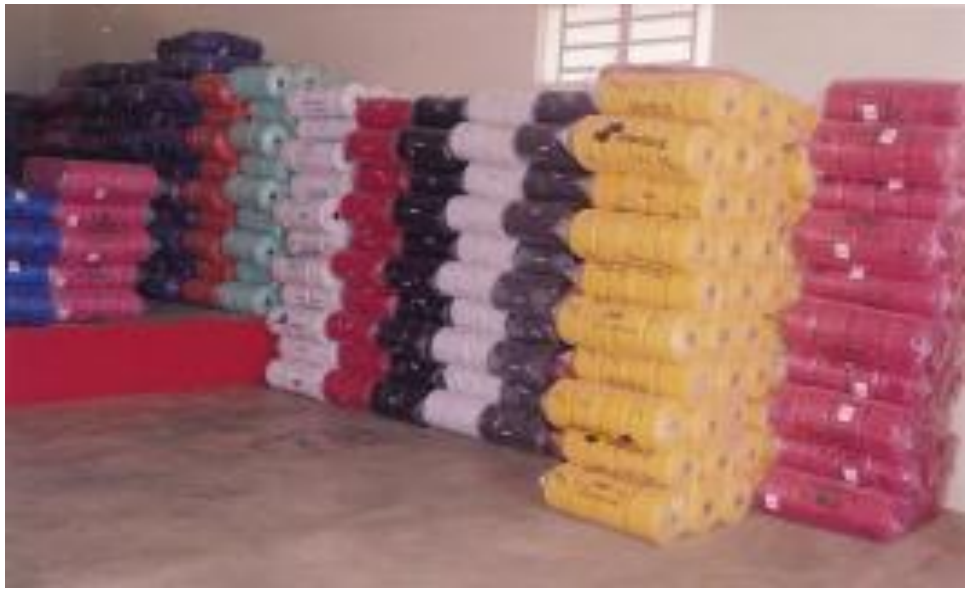

Foto 5: São Bento-PB: fios de algodão em cores vendido em depósito. Foto: Carneiro, 2006. 


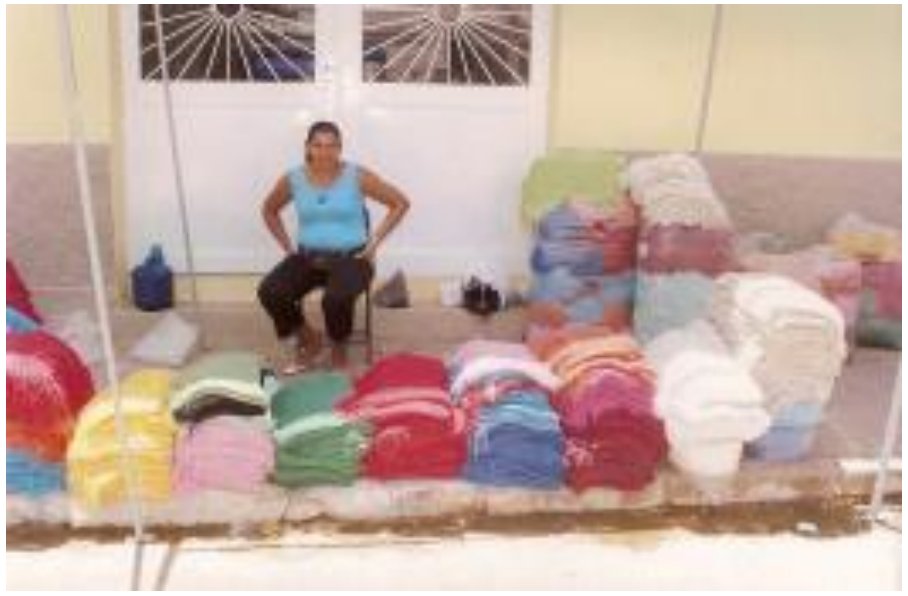

Foto 6: São Bento-PB: varanda fabricada em máquina. Foto: Carneiro, 2006.

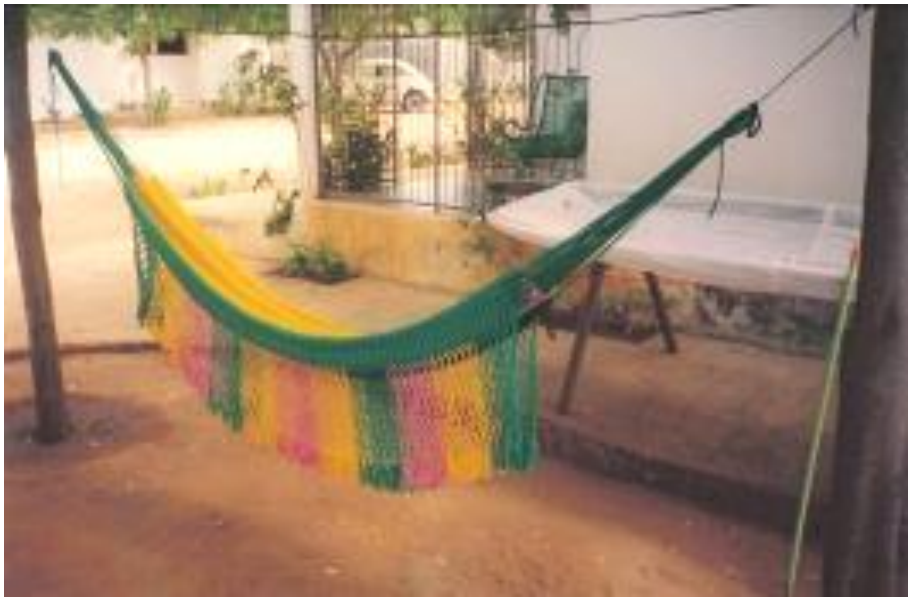

Foto 7: São Bento-PB: rede de dormir de cordões de poliéster. Foto: Carneiro, 2006. 
A comercialização dos produtos têxteis fabricados em São Bento hoje, se realiza em moldes semelhantes à realizada no período técnico local - quando da expansão comercial regional do artesanato -, e no período técnico-científico, da criação da manufatura. Isto é, sendo feita de forma ambulante por vendedores de rua indo de "porta em porta" com o produto nos ombros, percorrendo centenas de quilômetros a pé nos mais variados lugares do Brasil e da América do Sul. O motorista do veículo geralmente é o encarregado de distribuir a mercadoria para os corretores e de fazer a contabilidade e pagamentos das vendas. $\mathrm{O}$ vendedor ambulante ou corretor não possui vínculo empregatício formalizado e sua remuneração é por produção, ou seja, se o valor da mercadoria for estipulado em " $\mathrm{x}$ " Reais ele deverá vendê-la por x', x" etc., correspondendo essa diferença ao seu lucro. Caso venha a vender a rede ou outro produto pelo mesmo preço " $\mathrm{x}$ " estipulado pelo dono do veículo, ele terá direito a uma pequena comissão "que é pra ele poder comer, para sobrevivência dele" (Informação Verbal, 2001).

Essa comercialização na atualidade incluiu estratégias de venda inovadoras, tais como a adaptação de veículos com alto-falantes e que são chamados, na cidade, de "bocas de ferro"; e formas avançadas, como a exportação de produtos para países europeus e para os Estados Unidos. A distribuição dos produtos é realizada de formas variadas: ela é feita por alguns produtores, que, nesse caso, possuem veículo próprio e fazem, além da distribuição, a comercialização; por comerciantes que se dedicam exclusivamente à venda desses produtos (redes, etc.) e possuem também veículos próprios - são eles os que mais utilizam o expediente comercial das bocas de ferro. Essas, não se limitam a caminhonetes mas podem abranger as fozinhas e mecedinhas. E, por último, tem-se a distribuição realizada por meio de fretes de transportadoras locais, que dispõem de caminhões para prestar esse tipo de serviço aos produtores e negociantes de redes e demais artigos têxteis produzidos em São Bento.

Inovação comercial importante ocorreu na década de 1990 no que tange ao mercado internacional, embora limitada, pela qual a empresa Redes Santa Luzia consegue inserir-se no sistema internacional de trocas e exportar seus produtos. Seu mercado básico inclui os Estados Unidos e a Suíça, já tendo exportado também para Peru, Finlândia e França. Os produtos de exportação ainda se constituem raridade na cidade e isto, conforme um empresário local, se deve talvez "[...] a burocracia muito grande, a gente tem que fazer uma licitação, tem que colocar uma pessoa especializada para fazer esse tipo de venda, tem que ser uma mercadoria totalmente com etiqueta e isso traz algumas dificuldades na fabricação 
desses produtos e também na saída" (Informação Verbal apud CARNEIRO, 2001, p. 55).

Essa condição, advinda diretamente de uma especialização produtiva que busca tornar-se extrema nesse início de século XXI, representa, no entanto, mais que uma integração ao período técnico-científicoinformacional, a completa alienação humana e espacial de um lugar cuja identidade territorial e cultural tende a desaparecer. Isso em função, de um lado, da dissolução das horizontalidades e ampliação das verticalidades tornadas indispensáveis ao progresso técnico e tecnológico dessa atividade e, por outro, da própria reprodução socioespacial da sociedade em tela, conforme assiná-la Santos:

A especialização crescente da produção, numa base regional mas não raro ligada a interesses distantes, assim como a multiplicação das trocas, contribuem igualmente para tornar o homem estranho ao seu trabalho, estranho ao seu espaço, à sua terra, transformada praticamente em fábrica (1982, p. 19).

A importância que a fabricação de redes de dormir em São Bento adquire, local e regionalmente, se expressa através da mudança na organização de sua economia urbana. Fato bastante ilustrativo é o de que até o final da década de 1970, momento no qual se implanta o sistema bancário no município - em 1978 uma agência do Banco do Brasil e, já na primeira metade da década seguinte, uma do Bradesco, - o financiamento produtivo se dava nas agências de Caicó, no Rio Grande do Norte, onde São Bento se encontrava sob a jurisdição de sua agência do Banco do Brasil, para a obtenção de crédito.

São Bento insere-se no modelo de desenvolvimento sociopolítico e econômico do Brasil, adotado a partir da década de 1950, e nas contradições inerentes ao modo de produção capitalista, que se baseia na lei do desenvolvimento desigual e combinado. Logo, deve-se buscar incluílo nessa problemática geral que governa as ações em nível mais elevado para que se possa compreender a sua particularidade, pois, conforme Carlos (1992, p 90), "o lugar se produz na articulação contraditória entre o mundial que se anuncia e a especificidade histórica do particular".

Nota-se também, que a atividade têxtil local está complementada por diversas atividades econômicas sem as quais não seria possível a sua reprodução espacial, tais como a fabricação de cordões e fios de varanda, a comercialização de insumos industriais (teares, peças e acessórios), de produtos químicos (cloro e tintas) e de sua matéria-prima básica, o fio de 
algodão. Por outro lado, existe uma gama de atividades complementares ligadas a distribuição da produção, tais como as prensas, além de pessoal especializado no frete de veículos para entrega dos produtos têxteis nos mais variados locais do país.

O processo de mecanização da indústria têxtil de São Bento, sua produção, organização e reorganização do espaço se realizam em um contexto mais amplo que é o nacional, movido, porém, pela lei do desenvolvimento desigual e combinado presente no modo de produção capitalista, ou, como diz Smith (1988, p. 221) "O desenvolvimento desigual é tanto o produto quanto a premissa geográfica do desenvolvimento capitalista. [...]. O desenvolvimento desigual é a desigualdade social estampada na paisagem geográfica para certos fins sociais determinados".

\section{Conclusão}

A indústria têxtil de redes de dormir de São Bento é mais recente que a tradicional indústria de Jaguaruana, no Ceará. Esta tem origem indígena ao passo que aquela é resultante da ocupação humana do final do século XIX, de vaqueiros e da igreja católica. Jaguaruana é o segundo centro produtor de redes de dormir mais importante do Brasil.

Chamamos atenção para estes fatos históricos a fim de que os mesmos sirvam como parâmetros comparativos da primazia produtiva que a fabricação deste artefato de uso generalizado no Brasil tomou em São Bento, tornando a cidade reconhecida nacionalmente como "a capital mundial das redes". Esta condição foi fruto de seguidas inovações técnicas e produtivas pelas quais sua principal atividade passou desde o final do século XIX, mas, sobretudo no século XX.

A passagem do artesanato para a manufatura foi acompanhada por um conjunto de inovações, sobretudo nas relações de produção cujo corolário se dá com a implantação da maquinofatura, isto é, com a substituição dos processos manuais pelos processos mecânicos na fase de fabricação direta das redes de dormir e produtos substitutos.

O espaço de São Bento acompanha de perto estas transformações produtivas, assim, a cada período histórico local - os períodos artesanal, manufatureiro e mecanizado - correspondeu e corresponde um meio geográfico particular. Tivemos, portanto, a passagem de um meio natural, e em seguida técnico, para outro, com a presença da ciência e da informação 
já como meio técnico-científico-informacional, sobretudo a partir da década de 1990.

Este meio é certamente incompleto, mas garante a São Bento o controle de uma vasta área produtiva em seu entorno, ligada a produção, comercialização e distribuição de artigos têxteis, bem como um mercado de proporções hoje internacional pela exportação, em geral, de redes de dormir para a Europa, América Latina e Oceania.

O uso de corantes e cloro, importantes poluentes do rio Piranhas, está sendo deixado de lado durante o processo de fabricação, pela incorporação de fios de algodão que já saem coloridos das fiações ou dispensam o uso do cloro para clareamento, e, em menor proporção, pelo plantio e incorporação do algodão colorido no sistema de fabricação de redes tipo exportação e de alto custo para nichos de mercado específicos, como turistas e classes sociais de alto poder aquisitivo.

Trata-se assim, de um caso de sucesso, de uma cidade que emerge não da agricultura ou pecuária mas da atividade industrial no alto sertão paraibano; e, de uma atividade resultante do empreendedorismo local, da criatividade e do trabalho humano de sertanejos que souberam manter as tradições locais, mas que, acima de tudo, souberam se conectar às modernidades em curso no país e às diversas regiões nacionais a partir das trocas comerciais e de informação.

ESPAÇO, INOVAÇÃO E INDÚSTRIA TÊXTIL DE REDES DE DORMIR EM SÃO BENTO-PB: DO MEIO NATURAL AO MEIO TÉCNICO-CIENTÍFICO-INFORMACIONAL

Resumo: $O$ meio técnico-científico-informacional enquanto face geográfica do espaço brasileiro a partir de 1970 se constitui, obrigatoriamente, pela presença de técnica, ciência e informação. Esses elementos se difundem desigualmente no espaço e no tempo pelos municípios brasileiros, especialmente naqueles menos desenvolvidos. Neste contexto, busca-se entender a passagem do meio técnico para o meio técnico-científico-informacional de São Bento, na Paraíba, a partir de suas relações com os processos inovadores de sua indústria têxtil de fabricação de redes de dormir. Tal estudo é resultado de discussões empreendidas anteriormente (CARNEIRO, 2001; 2006; 2011) com base em Santos (1999). A cada fase desta indústria têxtil corresponde um conjunto de processos e produtos inovadores que resultaram em um meio geográfico particular, assim, no período artesanal emergiu o meio técnico; no período 
manufatureiro, o meio técnico-cientifico; e no período maquinofatureiro, o meio técnico-científico-informacional local.

Palavras-chave: Meio técnico-científico-informacional. Inovações. Indústria têxtil de redes de dormir. São Bento-PB.

SPACE, INNOVATION AND TEXTILE INDUSTRY OF HAMMOCKS IN SÃO BENTO-PARAÍBA: FROM THE NATURAL TO THE SCIENTIFIC-TECHNICAL INFORMATION ENVIRONMENT

Abstract: The technical-scientific-informational environment as a face of Brazilian geographical space since 1970s, it was, necessarily, forged by the presence of science and technical information. These elements were unevenly spread in space and time in Brazilian municipalities, especially in those least developed ones. In this context, we seek to understand the passage from technical environment to a scientific-technical-informational environment in São Bento, Paraíba - Brazil, from its relations with the innovative processes of textile industry of hammocks. This study results from previous discussions taken in some of our others works $(2001,2006$ and 2011) based on Santos (1999). Each development stage of textile industry has a set of innovative products and processes that have resulted from a particular geographical environment. So during the handcraft period emerged the technical environment, in the manufacturing period had arisen the scientific and technical environment, and finally in the industrial period came the local technical-scientific-informational environment.

Keywords: Technical-scientific-informational environment. Innovations. Textile industry. São Bento-PB.

\section{BIBLIOGRAFIA}

ARAÚJO, J. L. L. (1985). A atividade de confecção artesanal de redes de dormir - como estratégia de sobrevivência - e a organização do espaço em Pedro II. 291 f. Dissertação (Mestrado em Geografia) - Centro de Filosofia e Ciências Humanas, Universidade Federal de Pernambuco. Recife.

CARLOS, A. F. A. (1992). Espaço e indústria. 5. ed. São Paulo: Contexto. CARNEIRO. (2001). A indústria têxtil em São Bento PB: da manufatura à maquinofatura. 58 f. Monografia (Graduação em Geografia) - Centro de 
Educação, Universidade Estadual da Paraíba, Campina Grande.

(2006). Produção do espaço e circuitos de fluxos da indústria têxtil de São Bento-PB: do meio técnico ao meio técnico-científicoinformacional. 138 f. Dissertação (Mestrado em Geografia) - Centro de Filosofia e Ciências Humanas, Universidade Federal de Pernambuco. Recife.

. (2011). As semelhanças, diferenças e interações dos circuitos de fluxos socioespaciais de redes de dormir do Nordeste brasileiro. 100f. Tese (Doutorado em Geografia), Universidade Federal de Pernambuco. Recife.

CORRÊA, R. L. (1991). O espaço urbano. 3. ed. São Paulo: Ática.

DIAS, L. C. (2000). Redes: emergência e organização. In: CASTRO, I. E. de; G.OMES, CASTRO, I. GOMES, P.C.;CORREA, R. L. (Org.). (1995). Geografia: conceitos e temas. Rio de Janeiro: Bertrand Brasil, pp. 141-162. DOBB, M. (1983). A evolução do capitalismo. Rio de Janeiro: Zahar.

HARNECKER, M. (1983). Os conceitos elementares do materialismo histórico. 2. ed. rev. Rio de Janeiro: Global.

MARX, K. (1985). O capital. Livro I, v. 1. São Paulo: DIFEL.

RATTNER, H. (1980). Tecnologia e sociedade: uma proposta para os países subdesenvolvidos. São Paulo: Brasiliense.

ROCHA, J. B. V. da. (1983). São Bento: estudo sobre a manufatura de redes-de-dormir. João Pessoa: CGS.

SANTOS, M. (1982). Pensando o espaço do homem. São Paulo: Hucitec.

. (1988). Metamorfoses do espaço habitado: fundamentos teóricos e metodológicos da geografia. 3. ed. São Paulo: Hucitec.

- (1998). Técnica, espaço, tempo: globalização e meio técnicocientífico-informacional. 4. ed. São Paulo: Hucitec.

. (1999). A natureza do espaço: técnica e tempo, razão e emoção. 3. ed. São Paulo: Hucitec.

; SILVEIRA, M. L. (2004). O Brasil: território e sociedade no início do século XXI. 6. ed. Rio de Janeiro: Record.

SMITH, N. (1988). Desenvolvimento desigual: natureza, capital e a 
produção de espaço. Tradução de: Eduardo de Almeida Navarro. Rio de Janeiro: Bertrand Brasil.

Data de submissão: 03/06/2013

Data de aprovação: 18/09/2014 